\title{
European Journal of Engineering Education
}

ISSN: 0304-3797 (Print) 1469-5898 (Online) Journal homepage: http://www.tandfonline.com/loi/ceee20

\section{Breaking the habit: engineering students' understanding of mathematical creativity}

\section{Paula Catarino, Maria M. Nascimento, Eva Morais, Helena Campos \& Paulo Vasco}

To cite this article: Paula Catarino, Maria M. Nascimento, Eva Morais, Helena Campos \& Paulo Vasco (2017): Breaking the habit: engineering students' understanding of mathematical creativity, European Journal of Engineering Education, DOI: 10.1080/03043797.2017.1367760

To link to this article: https://doi.org/10.1080/03043797.2017.1367760

曲 Published online: 05 Nov 2017.

Submit your article to this journal $₫$

III Article views: 35

Q View related articles ¿ك

View Crossmark data $\llbracket$ 


\title{
Breaking the habit: engineering students' understanding of mathematical creativity
}

\author{
Paula Catarino (D), Maria M. Nascimento (D), Eva Morais (D), Helena Campos (i) and \\ Paulo Vasco (1)
}

Departamento de Matemática da Escola de Ciências e Tecnologia, University of Trás-os-Montes e Alto Douro, Vila Real, Portugal

\begin{abstract}
In higher education, engineering students have to be prepared for their future jobs, with knowledge but also with several soft skills, among them creativity. In this paper, we present a study carried on with 128 engineering undergraduate students on their understanding of mathematical creativity. The students were in the first year of different engineering first degrees in a north-eastern Portuguese university and we analysed the content of their texts for the question 'What do you understand by mathematical creativity?'. Data collection was done in the first semester of the academic years 2014/2015 and 2016/2017 in a Linear Algebra course. The results showed that 'problem solving' category had the majority of the references in 2014/2015, but not in the academic year 2016/2017 were 'involving mathematics' category had the majority. This exploratory study pointed out for 'problem solving' and 'involving mathematics' categories and gave us hints for teaching mathematics courses in engineering degrees.
\end{abstract}

\section{ARTICLE HISTORY}

Received 7 April 2017

Accepted 8 August 2017

\section{KEYWORDS}

Creativity; mathematical creativity; engineering;

higher education

\section{Introduction}

'Engineers are responsible for technological development that has created our modern society; they have built infrastructure, industrial production, mechanized agriculture, modern transportation systems, and technological innovations such as mass media, computers, and communication systems' (UNESCO 2010, 7) and so on we may add. In the same page of that report it is also written that 'United Nations Millennium Development Goals will require significant effort by engineers, but also creativity because the contexts of developing countries often requires new ways of doing things or the rediscovery of traditional techniques' (UNESCO 2010, 7).

Creativity and innovation skills like being curious using the existing knowledge to have new ideas, make new products, or develop new processes is referred by Cobo (2013) as one of his 'compendium of the key soft skills'. In addition, Zhou (2012) refers that the 'development of creativity in engineering education can be enabled through a series of strategies, which include using thinking tools, building a learning environment conductive to creativity, and learning by problem-solving'. So higher education institutions are compelled to rebuild their curricula and include soft skills such as creativity (e.g. Badran 2007) to keep up with industry and other jobs of engineers. Since we teach mathematics to engineering students, we were interested about their definitions of creativity already presented (Catarino et al. 2015, 2016) and in the present work we analysed the students' understanding of mathematical creativity. It is important to know what idea students have of creativity in order to devise a 
way to 'teach' or to infuse creativity in mathematics courses (e.g. Linear Algebra (LA), Statistics) in all engineering degrees.

We asked the students to write their definition of mathematical creativity and our research questions were 'What is the first year engineering students understanding of mathematical creativity? Is it different in the two academic years?'.

The methodology followed was qualitative based in a content analysis; so all the 128 freshmen students' texts (61 in 2014/2015 and 67 in 2016/2017) about mathematical creativity were collected and categorised. The categories of the content analysis were also crossed with other data as gender in order to describe the students' understanding of mathematical creativity.

\section{Background}

\subsection{Creativity}

In a broad sense, Torrance (1977) mentioned 'creativity occurs whenever people solve problems for which they had no previous learned or practice solution'. Kaufman (2009) said '[c]reativity occurs when a domain is changed in some way'. Creative people have either 'tiny creative leaps' or 'genuine breakthroughs' and all 'of them require that the individuals "go beyond where they have ever gone before"'. Several papers (e.g. Torrance 1977; Sriraman 2004; Badran 2007; Zhou 2012; Leikin et al. 2013) refer different definitions for creativity and also different points of view for it but, focusing on the final product of a creative activity, Amabile (2013) refers that ' $[t]$ he two main criteria for a creative product are originality (...) and usefulness'. In engineering, several authors (e.g. Zhou 2012; Morin, Robert, and Gabora 2014) point to the importance of problem-solving for engineers. Finally, Leikin et al. (2013) wrote that if you ask students' definitions of creativity, a lot of them would answer that creativity is 'thinking outside the box'.

\subsection{Mathematical creativity}

Based on the definition of creativity from Sriraman (2004), we may define mathematical creativity as 'the production of a novel and appropriate response, product, or solution to an open-ended task'. Analogously to the definition of creativity, mathematical creativity definition is also difficult and challenging as mentioned by Nadjafikhah, Yaftian, and Bakhshalizadeh (2012). The mathematical creativity is also described in the literature not only connected to the mathematical areas but also as a central scientific area 'that allows sustaining social technological and scientific progress in a variety of areas offering scientists and Hi-tech specialists a powerful apparatus and models for the analysis of situations, prognoses and processes'. A variety of aspects of mathematical creativity are mentioned in several studies, some authors use historical examples of mathematical creation (e.g. Torrance 1977; Eysenck 1994; Leikin et al. 2013), how to measure it using tests (e.g. Eysenck 1994; Kaufman 2009), and others detail it in terms of stages needed for the mathematical creation (e.g. Torrance 1977; Amabile 2013). Since we want to foster mathematical creativity in the mathematics courses, we present some of the definitions of the authors. Laycock's (1970) definition emphasises that 'mathematical creativity as an ability to analyze a given problem in many ways, observe patterns, see likenesses and differences, produce multiple ideas and decide upon a suitable method to tackle unfamiliar mathematical situation'. For Sriraman (2004)

it is sufficient to define creativity as the ability to produce novel or original work, which is compatible with my personal definition of mathematical creativity as the process that results in unusual and insightful solutions to a given problem, irrespective of the level.

Nadjafikhah, Yaftian, and Bakhshalizadeh (2012) stated that '[m]athematical creativity is not only related to the novel work of mathematicians but also discovering something not already known by one even if the result is hitherto known to others'. Nevertheless, the same authors approached 
mathematical creativity and learning mathematics saying: 'Solving such challenging mathematics problems [ill posed or open ended] could lead students to experience creativity in doing mathematics and also try to think as a mathematician, which means that students are encouraged to reflect on their own ideas'. Leikin et al. (2013; quoting Eysenck 1994) refer that 'mathematical creativity is observed when one generates a nonstandard solution for a problem which may not be solved by using a standard method'.

\subsection{Creativity in engineering}

Several authors (e.g. Zhou 2012; Daly, Mosyjowski, and Seifert 2014; Morin, Robert, and Gabora 2014) mention creativity as a soft skill need for all degrees and especially in engineering degrees. For instance, in Zhou (2012) and Walsh et al. (2013), 'solving problems' often is mentioned in engineering creativity, as it was implicit in the mathematical creativity definitions where problems were 'mathematical problems'. Daly, Mosyjowski, and Seifert (2014) wrote that '[t]he ability to engage in a creative process to solve a problem or to design a novel artifact is essential to engineering as a profession'. Definitions of engineering creativity also use words such as novelty, originality (new ideas), and usefulness (functionality, practicality, and applicability). Using these words, definitions of creativity (e.g. Torrance 1977) and mathematical creativity (e.g. Zhou 2012; Daly, Mosyjowski, and Seifert 2014) shared all the ideas; so all those definitions' analysis was needed in order to have an idea to frame the engineering students' definitions.

\section{Methodology}

In September 2014, an online survey on Google Drive was made available to a group of first-year engineering students (freshmen) from a north-eastern Portuguese university that enrolled an LA course. A total of 61 undergraduate students ${ }^{1}$ from 4 degrees participated in the survey: Biomedical Engineering (Biomedical Eng., 17 students, 27.9\%; 58.0\% women and 42.0\% men); Bioengineering (Bioeng., 12 students, 19.7\%; 67.0\% women and 33.0\% men); Mechanical Engineering (Mechanical Eng., 23 students, 37.7\%; 1 woman, 4.0\% and 96.0\% men); and Energy Engineering (Energy Eng., 9 students, $14.8 \%$; 1 woman, $11.0 \%$ and $89.0 \%$ men). Men were the mode (41 men, $67.0 \%$ and 20 women, 33.0\%). The participants' ages ranged between 17 and 25 years, although women were younger, whose ages ranged between 17 and 19 years. In September 2016, another group of firstyear engineering students from the same university enrolled in the same LA course did the same survey. A total of 67 students from 4 degrees participated in the survey: Biomedical Engineering (Biomedical Eng., 18 students, 26.9\%; 88.9\% women and $11.1 \%$ men); Bioengineering (Bioeng., 14 students, 20.9\%; 64.3\% women and 35.7\% men); Mechanical Engineering (Mechanical Eng., 27 students, 40.3\%; 1 woman, 3.7\% and 96.3\% men); and Integrated Master's in Industrial Management and Engineering (MIEGI, 8 students, $11.9 \% ; 37.5 \%$ women and $62.5 \%$ men). Men were also the mode (29 women, $43.3 \%$ and 38 men, $56.7 \%)$.

In both surveys, all participants, in both academic years, shared the same LA teacher, and some students were repeating this LA course. In order to make a comparative study with the results in Catarino et al. (2016), we followed the same qualitative methodology based on a content analysis (Catarino et al. 2016). The content analysis revealed group of words in the students' texts about their understanding of mathematical creativity so categories derived from the raw data each student text and the mathematical creativity definitions (Cohen, Manion, and Morrison 2011). In the survey, students wrote their own answers to the question 'What do you understand by mathematical creativity?' and also to their gender and their ages. They answered individually in the last 15 minutes of an LA class during the first semester of the academic years 2014/2015 and 2016/2017.

All the 128 freshmen's definitions (61 in 2014/2015 and 67 in 2016/2017) were available in a spreadsheet that was downloaded from the Google Drive form, where each student wrote their definition. Next, the definitions were categorised to describe the students' understanding of 
mathematical creativity. Two of the authors did the categorisation for each answer inductively based on all of the written text: words and sentences. After that the other authors confirmed that the categorisation and the subcategories were established. Each answer was included in a subcategory, and due to the amount of subcategories the authors agreed to reduce them to broader categories. Therefore, this content analysis was applied 'to the manifested content that is to words, paragraphs and sentences written, and we established the content analysis categories' (Krippendorff 2004, 105), which was students' written understanding of mathematical creativity. We read all the 128 texts word-by-word and derived codes by highlighting their important meanings and all of them were considered anonymously. Finally, eight subcategories emerged and a sentence example was selected for each category in each academic year (Table 1).

Table 1. Subcategories for mathematical creativity and examples in both academic years.

\begin{tabular}{|c|c|}
\hline \multirow[b]{2}{*}{ Subcategory } & Example of partici \\
\hline & $2014 / 2015$ \\
\hline $\begin{array}{l}\text { Applications of } \\
\text { mathematics to other } \\
\text { areas }\end{array}$ & $\begin{array}{l}\text { Mathematical creativity is to find, or to create new } \\
\text { mathematical problems that can be applied in } \\
\text { real life or new ways to solve existing problems } \\
\text { in order to make its resolution easier. }\end{array}$ \\
\hline $\begin{array}{l}\text { Connections between } \\
\text { mathematical } \\
\text { concepts }\end{array}$ & $\begin{array}{l}\text { Mathematical creativity is to take on mathematical } \\
\text { concepts already formulated and combining } \\
\text { them in order to reach a more comprehensive } \\
\text { and simplified method. All the mathematical } \\
\text { areas are related to each other and the creative } \\
\text { factor lies in intertwining them in order to reach } \\
\text { the resolution of the problem. }\end{array}$ \\
\hline $\begin{array}{l}\text { Creation and } \\
\text { innovation in } \\
\text { Mathematics }\end{array}$ & $\begin{array}{l}\text { Mathematical creativity is to create several } \\
\text { problems in mathematics and its resolution, } \\
\text { thereby contributing to the evolution of the field } \\
\text { of mathematics. }\end{array}$ \\
\hline $\begin{array}{l}\text { Multiple ways to solve a } \\
\text { problem }\end{array}$ & $\begin{array}{l}\text { Mathematical creativity (...) is related to } \\
\text { mathematical thinking, which is addressing this } \\
\text { issue in a different way. An example that lets you } \\
\text { explore the mathematical creativity is solving } \\
\text { problems because sometimes it allows using } \\
\text { different ways of doing it. }\end{array}$ \\
\hline Out of the box & $\begin{array}{l}\text { Apply new thinking to mathematics; try new things } \\
\text { in order to be able to discover mathematical } \\
\text { models. Being creative helps us not to close on } \\
\text { what already exists; we are more open to } \\
\text { experience that which has not yet tried by } \\
\text { anyone. }\end{array}$ \\
\hline
\end{tabular}

Mathematical thinking I consider it a form of reasoning to get the answer in another viable way.

Original or different way to solve a problem

Efficient way to solve a problem
The mathematical creativity is related to new ways of solving problems, since this leads to, who is creative in mathematics; find new solutions and new ways of solving problems.

Mathematical creativity is the 'ability' to find a way, a method or an efficient solution to solve the problem or the exercise correctly and not much confused.

\section{$2016 / 2017$}

The ability to apply mathematics to day-to-day situations, and relates it to physics and mechanics.

Mathematical creativity is the ability to create new theorems in order to understand the world around us. Some theorems and or even change others.

Mathematical creativity is the way a person can express through mathematical language and is linked to developments in the field of mathematics. For example, the improvement of mathematics resulted from the creativity and questioning it by several authors, which led them to discover new 'subjects' in this field.

Mathematical creativity is the ability to see a problem and immediately been able to see the possibility of solving it in different ways!

Mathematical creativity is the ability to solve or create problems related to mathematics, to the progress of the universe. We would not be able to make a technological breakthrough without mathematics, since most of the technology works from mathematical programs, so that mathematical creativity is essential if we are to evolve.

It is the way in which mathematics itself is used to do something original, to mix our imagination with it.

In my opinion mathematical creativity is a bit different from creativity in general.

Mathematical creativity is more related to reasoning, since having a greater capacity for reasoning makes it easier to solve any problem or think of a new one.

Mathematical creativity comes down to the act of solving problems in a proper and autonomous way. We can also understand how mathematical creativity is the ability to find new solutions, something new through a divergent thinking that will simplify the all resolution. 
Table 2. Adopted categories for mathematical creativity in both academic years.

\begin{tabular}{ll}
\hline Category & \multicolumn{1}{c}{ Grouped subcategories } \\
\hline $\begin{array}{c}\text { Involving } \\
\text { mathematics }\end{array}$ & $\begin{array}{c}\text { Applications of mathematics to other areas } \\
\text { Connections between mathematical concepts Creation and innovation in mathematics Mathematical } \\
\text { thinking } \\
\text { Multiple ways to solve a problem Original or different way to solve a problem Efficient way to solve a } \\
\text { problem } \\
\text { Out of the box }\end{array}$ \\
\hline
\end{tabular}

Next, we adopted the same categories for mathematical creativity that emerged in Catarino et al. (2016), namely: 'involving mathematics', 'problem solving', and 'out of the box' for both academic years (Table 2).

The exploratory descriptive analysis of the categories was done using IBM-SPSS version 22, and may be summarised as counting, percentages, tables, crossed tables (when other variables were considered). The data collected were tested for differences between the categories proportions ( $p$-value $<.05$, the proportions were different) for the total sample (all the 128 students) as well as by academic year. Each subset of variable vs. categories was tested for equality of proportions ( $p$-value $<.05$, the proportions were different), each subset of variable vs. categories was tested for independence ( $p$-value $<.05$, the variables were dependent). Due to the failure of the theoretic assumptions in some cases, we adopted Fisher's Exact Test ( $p$-value $<.05$, the variables were dependent). In order to give a graphical idea of the definitions of the students, we present a word $c$ loud $^{2}$, where 'words are arranged artistically in close proximity and the size of each word's type is proportional to the word's frequency or to the size of a numeric variable associated with the word' (word cloud n.d.). Although combinations of words are not captured, it is possible - by its size - to get a first indicator for the most used students' words in their definitions of mathematical creativity; so we may picture the most common impact of those students' definitions (e.g. DePaolo and Wilkinson 2014; Heimerl et al. 2014).

\section{Data analysis and discussion}

Comparing the 2 samples as 1 (with all the 128 students) 'problem solving' and 'involving mathematics' categories were not significantly different in both academic years $(p=.709>.05$, Table 3$)$; so the analysis crossing categories with gender and with degrees per academic year samples was the next approach. Although in Catarino et al. (2016) the students' mathematical creativity texts were mainly connected with 'problem solving' (60.7\%, 2014/2015 in Table 3), in the academic year 2016/2017 the category 'involving mathematics' had the majority (55.2\%, 2016/2017 in Table 3). In both cases and in each academic year the categories proportions were significantly different ( $p$-value $<.05$, Table 3 ). The 'out of the box' references in both academic years were residual (8.2\% in 2014/2015 and 4.5\% in 2016/2017, Table 3).

The word clouds' analysis used the translations of the Portuguese definitions texts for both academic years and for all 128 mathematical creativity definitions. Then we decided to sum the number of words counted in the webpage ${ }^{3}$ of the English texts if they had as much as 5 times the word in the given list (e.g. the list of 2014/2015 words from 'solve' with $19, \ldots$, until 'way' with 5 references for all the 116 references). In this way in the academic year of 2014/2015 were counted 116 words until 5 times the words appearance (13 different words) and in 2016/2017 were

Table 3. Proportions categories statistical tests for all students and by academic year.

\begin{tabular}{llllll}
\hline Categories proportions & All the students (128) & $p$-Value & $2014 / 2015$ & $2016 / 2017$ & $p$-Value \\
\hline 'Problem solving' & $56(47.3 \%)$ & $.709>.05$ & $37(60.7 \%)$ & $27(40.3 \%)$ & $.009<.05$ \\
'Involving mathematics' & $64(50.0 \%)$ & & $19(31.1 \%)$ & $37(55.2 \%)$ & $.002<.05$ \\
\hline
\end{tabular}




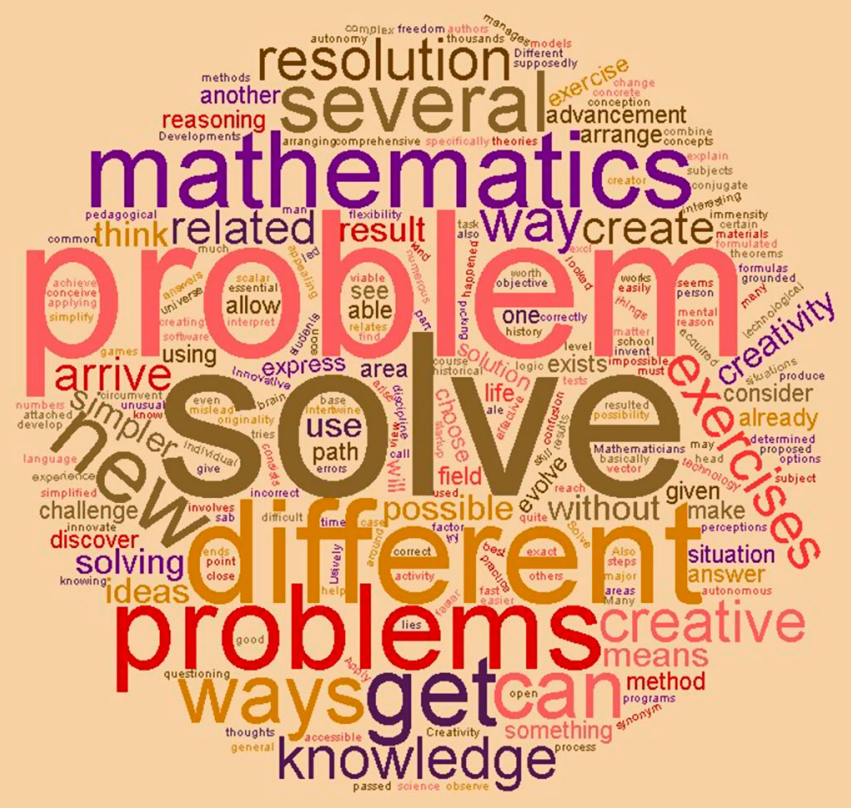

Figure 1. Word cloud from students' definitions 2014/2015.

counted 119 words until 5 times the words appearance (14 different words). Hence, the word clouds' of 2014/2015 (Figure 1) and of 2016/2017 (Figure 2) were built.

In Figure 1, 'solve' is the most frequent word (16\%, 19 out of the 116 references in the word counter) with parallel in a less-used word 'resolution' (6\%, 7 out of 116), 'problem' (15\%, 10 out of $116)$ in parallel with 'problems' (9\%, 10 out of 116). Afterwards 'different' (10\%, 12 out of 116) and 'mathematics' ( $8 \%, 9$ out of 116) showed. As a last remark, 'new' $(7 \%, 8$ out of 116$)$ and 'several' (6\%, 7 out of 116) were viewed and in parallel 'ways' and 'way' (6\%, 7 out of 116 and $4 \%, 5$ out of 116) were perceived.

This brief and exploratory analysis showed that the '[w]ord clouds treat each word as the unit of analysis' (McNaught and Lam 2010). However, if we try some connections with these words, some texts of the students' definitions may be obtained 'several ways to solve a problem', 'a different way to solve a problem' related with the 'problem solving' category. Another one may be 'to create several problems in mathematics and its resolution' as in a part of student definition in the category 'involving mathematics' in 2014/2015 (Table 1, subcategory 'Applications of mathematics to other areas'). As already seen, this rebuilding of the texts of the students definitions emphasises the 'problem solving' category (Table 1, within 2014/2015 categories).

In Figure 2, 'involving mathematics' was the most frequent category since 'mathematics' is the bigger word (11\%, 13 out of the 119 references in the word counter), followed by 'theorems' (10\%, 12 out of the 119). With smaller number 'new' and 'ability' (9\%, 11 out of the 119 for each different word); 'creativity' in parallel with 'create' ( $8 \%, 9$ out of the 119 for each different word), and 'solve' $(8 \%, 9$ out of the 119). As before 'ways' and 'way' also appear, 'problems' and 'problem' also in parallel and 'formulas' (each different word with a weight of $6 \%, 7$ out of the 119).

This word cloud also corroborates McNaught and Lam's (2010) words. If rebuilding the students' definitions is attempted, it is possible to re-write simple definitions like those in Table 1, the column of examples from $2016 / 2017$. For instance, 'the ability to create new theorems' as in a part of student 


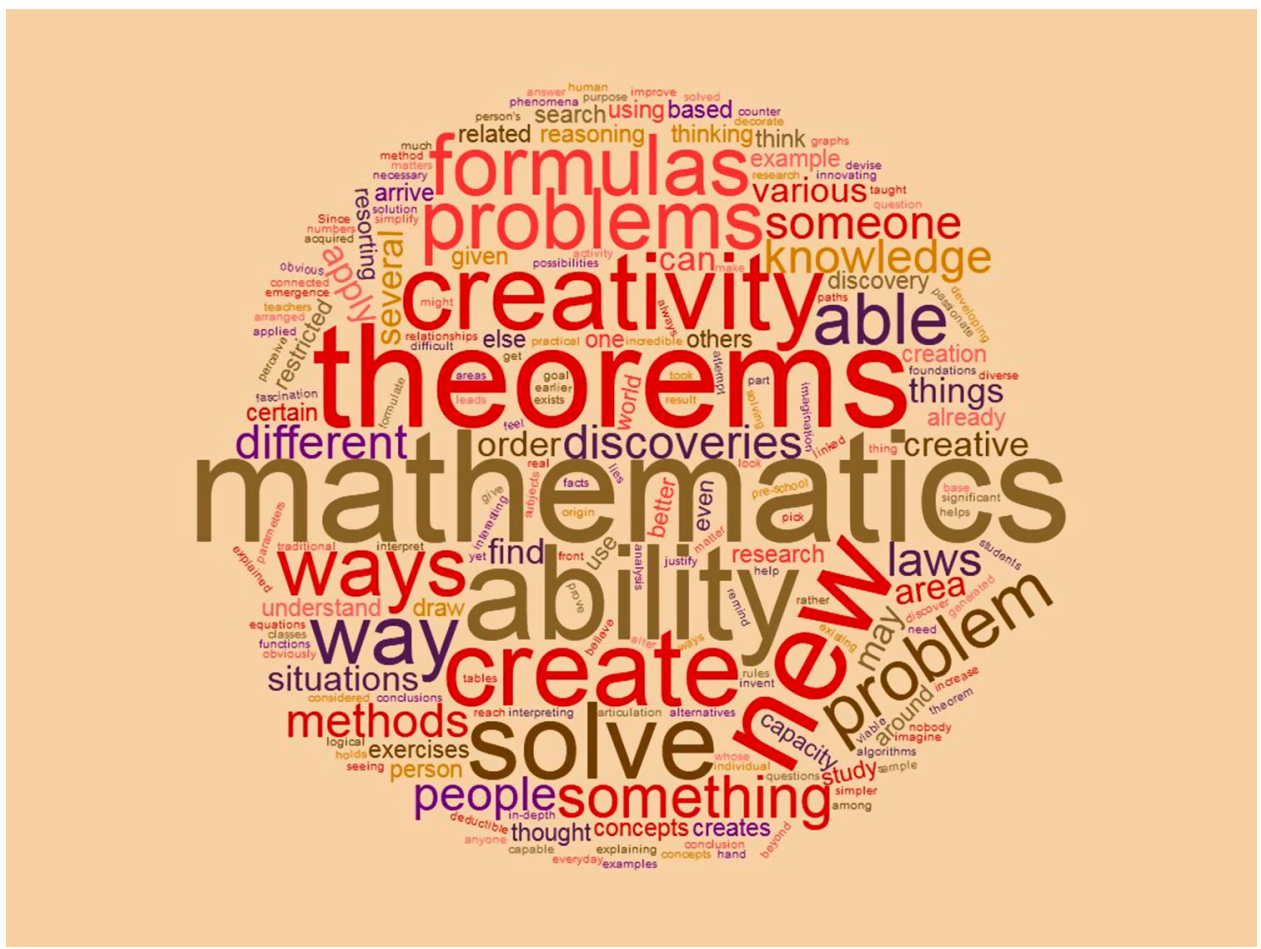

Figure 2. Word cloud from students' definitions 2016/2017.

definition in the category 'involving mathematics' (Table 1, subcategory 'Connections between mathematical concepts', 2016/2017), 'way ... mathematics ... is used to do something original' (Table 1, subcategory 'Mathematical thinking', 2016/2017) or even in the 'problem solving' category 'the act of solving problems in a proper and autonomous way' (Table 1, subcategory 'Efficient way to solve a problem', 2016/2017). As already seen this rebuilding of the texts of the students definitions emphasises now the 'involving mathematics' category (Table 1, within 2016/2017 categories).

Within gender, only $27.6 \%$ of the women associated their mathematical creativity definition with 'problem solving' much lower than in $2014 / 2015,65 \%$ (Table 4) in parallel $50 \%$ of the men still do the same association with 'problem solving', a little lower than in 2014/2015, 58.5\% (Table 4). The change in the 'involving mathematics' category is the opposite: $56.8 \%$ of the women associate their mathematical creativity definition with this category much higher than in 2014/2015, 31.6\% (Table 4); $42.1 \%$ of the men still do the same association a little lower than in 2014/2015, 31.7\% (Table 4).

Despite the independence observed for the same situation with students in 2014/2015 (Fisher's Exact Test $=0.41, p=.92>.05$; Catarino et al. 2016), the categories of the participants' texts in $2016 / 2017$ are not independent of the gender (Fisher's Exact Test $=6.573, p=.021<.05$ ). For now, we cannot explain this difference since beyond age and gender; no other data were collected, nor were interviews with the students made. Nevertheless, only $27.6 \%$ (8 out of the 29 women in $2016 / 2017$ ) choose 'problem solving' category and in that 'problem solving' category only $29.6 \%$ ( 8 out of the 27 that chose in 2016/2017) were women; these small proportions made the difference.

There is no difference in the proportions of students in each category for the academic year 2014/ 2015 (Catarino et al. 2016) and 2016/2017 (in both there proportions do not differ significantly, $p>.05$ ).

Although there were only three common degrees on the two academic years studied (Bioengineering, Biomedical Engineering and Mechanical Engineering), the groups of 'bio' and 'non-bio' engineering degrees are similar. In the academic year 2014/2015 there was a mode in references involving 'problem solving' category for all the degrees except Biomedical Engineering (Table 5) 
Table 4. Number of references by category and gender in the two academic years.

\begin{tabular}{|c|c|c|c|c|c|c|}
\hline \multirow{2}{*}{\multicolumn{4}{|c|}{ Academic year }} & \multicolumn{2}{|c|}{ Number of categories } & \multirow[b]{2}{*}{ Total } \\
\hline & & & & \multirow{2}{*}{$\begin{array}{c}\text { Women } \\
6\end{array}$} & \multirow{3}{*}{$\begin{array}{l}\text { Men } \\
13 \\
68.4 \%\end{array}$} & \\
\hline 2014 & Category & Involving mathematics & Count & & & 19 \\
\hline & & & $\%$ Between category & $31.6 \%$ & & $100.0 \%$ \\
\hline & & & $\%$ Between gender & $30.0 \%$ & $31.7 \%$ & $31.1 \%$ \\
\hline & & Problem solving & Count & 13 & 24 & 37 \\
\hline & & & $\%$ Between category & $35.1 \%$ & $64.9 \%$ & $100.0 \%$ \\
\hline & & & $\%$ Between gender & $65.0 \%$ & $58.5 \%$ & $60.7 \%$ \\
\hline & & Out of the box & Count & 1 & 4 & 5 \\
\hline & & & $\%$ Between category & $20.0 \%$ & $80.0 \%$ & $100.0 \%$ \\
\hline & & & $\%$ Between gender & $5.0 \%$ & $9.8 \%$ & $8.2 \%$ \\
\hline & Total & & Count & 20 & 41 & 61 \\
\hline & & & $\%$ Between category & $32.8 \%$ & $67.2 \%$ & $100.0 \%$ \\
\hline & & & $\%$ Between gender & $100.0 \%$ & $100.0 \%$ & $100.0 \%$ \\
\hline \multirow[t]{12}{*}{2016} & Category & Involving mathematics & Count & 21 & 16 & 37 \\
\hline & & & $\%$ Between category & $56.8 \%$ & $43.2 \%$ & $100.0 \%$ \\
\hline & & & $\%$ Between gender & $72.4 \%$ & $42.1 \%$ & $55.2 \%$ \\
\hline & & Problem solving & Count & 8 & 19 & 27 \\
\hline & & & $\%$ Between category & $29.6 \%$ & $70.4 \%$ & $100.0 \%$ \\
\hline & & & $\%$ Between gender & $27.6 \%$ & $50.0 \%$ & $40.3 \%$ \\
\hline & & Out of the box & Count & 0 & 3 & 3 \\
\hline & & & $\%$ Between category & $0.0 \%$ & $100.0 \%$ & $100.0 \%$ \\
\hline & & & $\%$ Between gender & $0.0 \%$ & $7.9 \%$ & $4.5 \%$ \\
\hline & Total & & Count & 29 & 38 & 67 \\
\hline & & & $\%$ Between category & $43.3 \%$ & $56.7 \%$ & $100.0 \%$ \\
\hline & & & $\%$ Between gender & $100.0 \%$ & $100.0 \%$ & $100.0 \%$ \\
\hline \multirow[t]{12}{*}{ Total } & Category & Involving mathematics & Count & 27 & 29 & 56 \\
\hline & & & $\%$ Between category & $48.2 \%$ & $51.8 \%$ & $100.0 \%$ \\
\hline & & & $\%$ Between gender & $55.1 \%$ & $36.7 \%$ & $43.8 \%$ \\
\hline & & Problem solving & Count & 21 & 43 & 64 \\
\hline & & & $\%$ Between category & $32.8 \%$ & $67.2 \%$ & $100.0 \%$ \\
\hline & & & $\%$ Between gender & $42.9 \%$ & $54.4 \%$ & $50.0 \%$ \\
\hline & & Out of the box & Count & 1 & 7 & 8 \\
\hline & & & $\%$ Between category & $12.5 \%$ & $87.5 \%$ & $100.0 \%$ \\
\hline & & & $\%$ Between gender & $2.0 \%$ & $8.9 \%$ & $6.3 \%$ \\
\hline & Total & & Count & 49 & 79 & 128 \\
\hline & & & $\%$ Between category & $38.3 \%$ & $61.7 \%$ & $100.0 \%$ \\
\hline & & & $\%$ Between gender & $100.0 \%$ & $100.0 \%$ & $100.0 \%$ \\
\hline
\end{tabular}

and, as previously mentioned, in 2016/2017 the 'involving mathematics' category was the mode for Bioengineering and Biomedical Engineering ( $32.8 \%$, that is 22 out of 67 , in the 2 degrees, Table 5). For Mechanical Engineering and MIEGI the most referred category was 'problem solving' $(25.4 \%$, that is 17 out of 67 , also in the 2 degrees, Table 5).

Without the participants that presented a text connected to the category 'out of the box' or are MIEGI students (2016/2017, Table 3), there is independence between the categories and the degrees (Fisher's Exact Test $=2.585, p=.275>.05$ ).

\section{Final remarks and future work}

Unlike Leikin et al. (2013) in our mathematical creativity we got more 'problem solving' (2014/2015), and 'involving mathematics' (2016/2017), perhaps because students were in their first year and semester in higher education engineering (freshmen).

The statistical analysis did not show differences between the proportions of the categories by gender or degree or even dependency or strong dependency between categories and other variables. However, the students mathematical creativity definition texts were mainly connected with 'problem solving' (2014/2015), and 'involving mathematics' (2016/2017). In both cases and in each academic year the differences between the categories proportions were significantly different $(p$-value $<.05$, Table 3). The 'out of the box' references were residual in both academic years. 
Table 5. Number of references by category and degree in the two academic years.

\begin{tabular}{|c|c|c|c|c|c|c|c|c|c|}
\hline \multirow{2}{*}{\multicolumn{2}{|c|}{ Academic year }} & & & \multicolumn{5}{|c|}{ Number of references } & \multirow[b]{2}{*}{ Total } \\
\hline & & & & Bioeng. & Biomed. & Mech. & Energy & MIEGI & \\
\hline \multirow[t]{16}{*}{2014} & Category & Involving mathematics & Count & 7 & 6 & 3 & 3 & & 19 \\
\hline & & & $\%$ Within category & $36.8 \%$ & $31.6 \%$ & $15.8 \%$ & $15.8 \%$ & & $100 \%$ \\
\hline & & & $\%$ Within degree & $41.2 \%$ & $50.0 \%$ & $13.0 \%$ & $33.3 \%$ & & $31.1 \%$ \\
\hline & & & $\%$ Of total & $11.5 \%$ & $9.8 \%$ & $4.9 \%$ & $4.9 \%$ & & $31.1 \%$ \\
\hline & & Problem solving & Count & 8 & 6 & 18 & 5 & & 37 \\
\hline & & & $\%$ Within category & $21.6 \%$ & $16.2 \%$ & $48.6 \%$ & $13.5 \%$ & & $100 \%$ \\
\hline & & & $\%$ Within degree & $47.1 \%$ & $50.0 \%$ & $78.3 \%$ & $55.6 \%$ & & $60.7 \%$ \\
\hline & & & $\%$ Of total & $13.1 \%$ & $9.8 \%$ & $29.5 \%$ & $8.2 \%$ & & $60.7 \%$ \\
\hline & & Out of the box & Count & 2 & 0 & 2 & 1 & & 5 \\
\hline & & & $\%$ Within category & $40.0 \%$ & $0.0 \%$ & $40.0 \%$ & $20.0 \%$ & & $100 \%$ \\
\hline & & & $\%$ Within degree & $11.8 \%$ & $0.0 \%$ & $8.7 \%$ & $11.1 \%$ & & $8.2 \%$ \\
\hline & & & $\%$ Of total & $3.3 \%$ & $0.0 \%$ & $3.3 \%$ & $1.6 \%$ & & $8.2 \%$ \\
\hline & Total & & Count & 17 & 12 & 23 & 9 & & 61 \\
\hline & & & $\%$ Within category & $27.9 \%$ & $19.7 \%$ & $37.7 \%$ & $14.8 \%$ & & $100 \%$ \\
\hline & & & $\%$ Within degree & $100 \%$ & $100 \%$ & $100 \%$ & $100 \%$ & & $100 \%$ \\
\hline & & & $\%$ Of total & $27.9 \%$ & $19.7 \%$ & $37.7 \%$ & $14.8 \%$ & & $100 \%$ \\
\hline \multirow{16}{*}{2016} & Category & Involving mathematics & Count & 10 & 12 & 12 & & 3 & 37 \\
\hline & & & $\%$ Within category & $27.0 \%$ & $32.4 \%$ & $32.4 \%$ & & $8.1 \%$ & $100 \%$ \\
\hline & & & $\%$ Within degree & $71.4 \%$ & $66.7 \%$ & $44.4 \%$ & & $37.5 \%$ & $55.2 \%$ \\
\hline & & & $\%$ Of total & $14.9 \%$ & $17.9 \%$ & $17.9 \%$ & & $4.5 \%$ & $55.2 \%$ \\
\hline & & Problem solving & Count & 4 & 6 & 13 & & 4 & 27 \\
\hline & & & $\%$ Within category & $14.8 \%$ & $22.2 \%$ & $48.1 \%$ & & $14.8 \%$ & $100 \%$ \\
\hline & & & $\%$ Within degree & $28.6 \%$ & $33.3 \%$ & $48.1 \%$ & & $50.0 \%$ & $40.3 \%$ \\
\hline & & & $\%$ Of total & $6.0 \%$ & $9.0 \%$ & $19.4 \%$ & & $6.0 \%$ & $40.3 \%$ \\
\hline & & Out of the box & Count & 0 & 0 & 2 & & 1 & 3 \\
\hline & & & $\%$ Within category & $0.0 \%$ & $0.0 \%$ & $66.7 \%$ & & $33.3 \%$ & $100 \%$ \\
\hline & & & $\%$ Within degree & $0.0 \%$ & $0.0 \%$ & $7.4 \%$ & & $12.5 \%$ & $4.5 \%$ \\
\hline & & & $\%$ Of total & $0.0 \%$ & $0.0 \%$ & $3.0 \%$ & & $1.5 \%$ & $4.5 \%$ \\
\hline & Total & & Count & 14 & 18 & 27 & & 8 & 67 \\
\hline & & & $\%$ Within category & $20.9 \%$ & $26.9 \%$ & $40.3 \%$ & & $11.9 \%$ & $100 \%$ \\
\hline & & & $\%$ Within degree & $100 \%$ & $100 \%$ & $100 \%$ & & $100 \%$ & $100 \%$ \\
\hline & & & $\%$ Of total & $20.9 \%$ & $26.9 \%$ & $40.3 \%$ & & $11.9 \%$ & $100 \%$ \\
\hline \multirow[t]{16}{*}{ Total } & Category & Involving mathematics & Count & 17 & 18 & 15 & 3 & 3 & 56 \\
\hline & & & $\%$ Within category & $30.4 \%$ & $32.1 \%$ & $26.8 \%$ & $5.4 \%$ & $5.4 \%$ & $100.0 \%$ \\
\hline & & & $\%$ Within degree & $54.8 \%$ & $60.0 \%$ & $30.0 \%$ & $33.3 \%$ & $37.5 \%$ & $43.8 \%$ \\
\hline & & & $\%$ Of total & $13.3 \%$ & $14.1 \%$ & $11.7 \%$ & $2.3 \%$ & $2.3 \%$ & $43.8 \%$ \\
\hline & & Problem solving & Count & 12 & 12 & 31 & 5 & 4 & 64 \\
\hline & & & $\%$ Within category & $18.8 \%$ & $18.8 \%$ & $48.4 \%$ & $7.8 \%$ & $6.3 \%$ & $100 \%$ \\
\hline & & & $\%$ Within degree & $38.7 \%$ & $40.0 \%$ & $62.0 \%$ & $55.6 \%$ & $50.0 \%$ & $50 \%$ \\
\hline & & & $\%$ Of total & $9.4 \%$ & $9.4 \%$ & $24.2 \%$ & $3.9 \%$ & $3.1 \%$ & $50 \%$ \\
\hline & & Out of the box & Count & 2 & 0 & 4 & 1 & 1 & 8 \\
\hline & & & $\%$ Within category & $25.0 \%$ & $0.0 \%$ & $50.0 \%$ & $12.5 \%$ & $12.5 \%$ & $100 \%$ \\
\hline & & & $\%$ Within degree & $6.5 \%$ & $0.0 \%$ & $8.0 \%$ & $11.1 \%$ & $12.5 \%$ & $6.3 \%$ \\
\hline & & & $\%$ Of total & $1.6 \%$ & $0.0 \%$ & $3.1 \%$ & $0.8 \%$ & $0.8 \%$ & $6.3 \%$ \\
\hline & Total & & Count & 31 & 30 & 50 & 9 & 8 & 128 \\
\hline & & & $\%$ Within category & $24.2 \%$ & $23.4 \%$ & $39.1 \%$ & $7.0 \%$ & $6.3 \%$ & $100 \%$ \\
\hline & & & $\%$ Within degree & $100 \%$ & $100 \%$ & $100 \%$ & $100 \%$ & $100 \%$ & $100 \%$ \\
\hline & & & $\%$ Of total & $24.2 \%$ & $23.4 \%$ & $39.1 \%$ & $7.0 \%$ & $6.3 \%$ & $100 \%$ \\
\hline
\end{tabular}

Since the categories of the freshmen's definitions of mathematical creativity in 2016/2017 are not independent from gender, we did not have enough data and we did not find references that gave a reason for this result. Maybe in future studies we could develop this aspect, studying it in larger samples and not only freshmen or undergraduate but also Master, or even Ph.D. students.

In this analysis, it was interesting to note that the world clouds built (Figures 1 and 2) in some way validated our previous content analysis categories (McNaught and Lam 2010), since we could even rebuilt some of the students' generic definitions and some presented as examples in Table 1. 
This exploratory study pointed out for 'problem solving' (number of references mode in 2014/ 2015) and 'involving mathematics' (number of references mode in 2016/2017) categories. Maybe the shift on the category is connected to the fact that secondary curricula were reformed in Portugal in 2013/2014 to a much more 'formal' mathematics, therefore the use of words such as 'theorems', and 'formulas', words that had almost no references in academic year 2014/2015. Even though in $2014 / 2015$ there were a lot more references in the 'problem solving' category, it is difficult - in some of the students definitions - to know if we were viewing problems in the 'mathematical' sense (e.g. Nadjafikhah, Yaftian, and Bakhshalizadeh 2012) or in the 'engineering' sense (e.g. Zhou 2012; Daly, Mosyjowski, and Seifert 2014; Morin, Robert, and Gabora 2014).

Nevertheless, these major references in this study gave us hints for teaching mathematics courses in engineering degrees. Different tasks may encourage mathematical creativity, hence creativity. Following this study for engineering degrees (at least the studied ones) in their mathematics courses for instance exploring problem-solving and problem-posing in other mathematical subjects such as in Statistics. The problem-based approach is possible since many of the statistical approaches are needed in engineering (e.g. Six Sigma as in Zhan, Fink, and Fang 2010).

Another strategy may be implemented with students also involving a peer review of the written resolutions of the colleagues' LA problems suggested in that course, a possible approach for students to discover different resolutions and propose mistakes' corrections to their colleagues and that is also a way to encourage reflecting on their own ideas (Nadjafikhah, Yaftian, and Bakhshalizadeh 2012). The implementation of peer-review tasks is already documented with engineering students in other engineering courses and degrees (e.g. Dominguez et al. 2014; Silva et al. 2016). During the second semester of this academic year 2016/2017, a creativity and cooperative learning intervention was done with Communication and Multimedia ${ }^{4}$ graduate students (in LA, a second semester course). According to the teachers involved in the research in 2017 the results showed that students who participated in the intervention scored significantly higher in the creativity test at the end.

Facing the today's work market needs for the future engineers, as already said, higher education institutions - like the north-eastern Portuguese where this study occurred - are required to rebuild their curricula and include soft skills such as creativity (e.g. Badran 2007; Morin, Robert, and Gabora 2014) in order to keep up with industry and other jobs of engineers.

\section{Notes}

1. In the Bologna three cycles programme, these were students from the first year of the first cycle.

2. Built using the free software available at http://www.wordclouds.com/.

3. http://www.wordclouds.com/.

4. A degree of the first cycle at the same School of Science and Technology that leads the Engineering degrees, one-cycle as in this study.

\section{Disclosure statement}

No potential conflict of interest was reported by the authors.

\section{Funding}

This work is funded by the National Funds through the Foundation for Science and Technology (Fundaç ão de Ciência e Tecnologia - FCT) under the UID/CED/00194/2013 project and the Pest-UID/MAT/00013/2013 project.

\section{Notes on contributors}

Paula Catarino is a researcher at CMAT (Center of Mathematics, Braga, Portugal) and CIDTFF (Research Centre on Didactics and Technology in the Education of Trainers, Aveiro, Portugal) and has been an associated professor at the University 
of Trás-os-Montes e Alto Douro (UTAD) since 1985, in Vila Real, Portugal, where she teaches Linear Algebra. Her main research interests are related with several number sequences defined by recurrence, semigroups of transformations, Mathematics Education, as well as the Ethnomathematics research field. And now, she also studies the critical thinking and mathematical creativity research fields in its connections to the area of mathematics.

Maria M. Nascimento is a researcher at CIDTFF and has been a lecturer at the University of Trás-os-Montes e Alto Douro (UTAD) since 1985, in Vila Real, Portugal, where she teaches Statistics and Operations Research. Her main research interests are related to teaching Statistics and its Attitudinal and Didactical issues, as well as the Ethnomathematics research field. Now, she is involved with the critical thinking research field in its connections to the statistical thinking.

Eva Morais has been a lecturer at University of Trás-os-Montes e Alto Douro since 2000, where she teaches courses of Statistics and Experimental Design. She is a member at CMAT and her main research interests are related to the study of methods used to solve partial differential equations in financial pricing models and she is also interested in the critical thinking in higher education research field.

Helena Campos is a researcher at CIDTFF and has been a lecturer at the University of Trás-os-Montes e Alto Douro (UTAD) since 1995, in Vila Real, Portugal, where she teaches Geometry and Didactics of Mathematics. Her main research interests are related to teaching Geometry and its Attitudinal and Didactical issues, as well as the several number sequences research field. Now, she studies the critical thinking and mathematical creativity research fields in its connections to the mathematical thinking.

Paulo Vasco is a researcher at CMAT and has been teaching at the University of Trás-os-Montes e Alto Douro (UTAD) in Vila Real, Portugal, since 2001, where currently he is serving an assistant professor, teaching mainly Linear Algebra at different courses, including several of engineering. His main research interests are related with numerical semigroups, several number sequences defined by recurrence as well as Mathematics Education. Recently, he has started studying the critical thinking and creativity research fields and its connections to the area of mathematics.

\section{ORCID}

Paula Catarino (iD) http://orcid.org/0000-0001-6917-5093

Maria M. Nascimento (iD http://orcid.org/0000-0002-3913-4845

Eva Morais (iD http://orcid.org/0000-0002-3815-9821

Helena Campos (D) http://orcid.org/0000-0003-2767-0998

Paulo Vasco (D) http://orcid.org/0000-0001-5460-4297

\section{References}

Amabile, T. M. 2013. "Componential Theory of Creativity." In Encyclopedia of Management Theory, edited by E. H. Kessler, 134-139. New York: Kluver.

Badran, Ibrahim. 2007. "Enhancing Creativity and Innovation in Engineering Education." European Journal of Engineering Education 32 (5): 573-585.

Catarino, Paula, Maria M. Nascimento, Eva Morais, Helena Campos, and Paulo Vasco. 2016. "Mathematical Creativity's Understanding in Engineering Students of a Portuguese University." In 2nd International Conference of the Portuguese Society for Engineering Education (CISPEE), 1-5. IEEE.

Catarino, Paula, Maria M. Nascimento, Eva Morais, Helena Silva, and Rita Payan-Carreira. 2015. "Take this Waltz on Creativity: The Engineering Students' Conceptions." In Book of Abstracts: II International Seminar on Critical Thinking: Current Challenges for Critical Thinking: Education, Development and Assessment, 55-56. II International Seminar on Critical Thinking, May.

Cobo, Cristobal. 2013. "Skills for Innovation: Envisioning an Education that Prepares for the Changing World." Curriculum Journal 24 (1): 67-85.

Cohen, Louis, Lawrence Manion, and Keith Morrison. 2011. Research Methods in Education. New York: Routledge.

Daly, Shanna R., Erika A. Mosyjowski, and Colleen M. Seifert. 2014. "Teaching Creativity in Engineering Courses." Journal of Engineering Education 103 (3): 417-449.

DePaolo, Concetta A., and Kelly Wilkinson. 2014. "Get Your Head into the Clouds: Using Word Clouds for Analyzing Qualitative Assessment Data." TechTrends 58 (3): 38-44.

Dominguez, Caroline, M. Nascimento, Ana Maia, D. Pedrosa, and G. Cruz. 2014. "Come Together: Peer Review with Energy Engineering Students." International Journal of Engineering Pedagogy 4 (5): 34-41.

Eysenck, G. 1994. "Mathematical Creativity." In Advanced Mathematical Thinking, edited by D. Tall, 42-45. New York: Kluwer.

Eysenck, Hans. 1994. "The Measurement of Creativity." In Dimensions of Creativity, edited by Margaret A. Boden, $199-234$. MIT Press. 
Heimerl, Florian, Steffen Lohmann, Simon Lange, and Thomas Ertl. 2014. "Word Cloud Explorer: Text Analytics Based on Word Clouds." In 47th Hawaii International Conference on System Sciences (HICSS), 1833-1842. IEEE.

Kaufman, Alan S. 2009. IQ Testing 101. New York: Springer.

Krippendorff, Klaus. 2004. Content Analysis: An Introduction to its Methodology. Thousand Oaks: Sage.

Laycock, Mary. 1970. "Creative Mathematics at Nueva." The Arithmetic Teacher 17 (4): 325-328.

Leikin, Roza, Rena Subotnik, Demetra Pitta-Pantazi, Florence Mihaela Singer, and Ildiko Pelczer. 2013. “Teachers' Views on Creativity in Mathematics Education: An International Survey." ZDM 45 (2): 309-324.

McNaught, Carmel, and Paul Lam. 2010. "Using Wordle as a Supplementary Research Tool." The Qualitative Report 15 (3): 630-643.

Morin, Sophie, Jean-Marc Robert, and Liane Gabora. 2014. "A New Course on Creativity in an Engineering Program: Foundations and Issues." In Proceedings of the 2014 International Conference on Innovative Design and Manufacturing (ICIDM), 270-275. IEEE.

Nadjafikhah, Mehdi, Narges Yaftian, and Shahrnaz Bakhshalizadeh. 2012. "Mathematical Creativity: Some Definitions and Characteristics." Procedia-Social and Behavioral Sciences 31: 285-291.

Silva, Helena, José Lopes, Caroline Dominguez, Rita Payan-Carreira, Eva Morais, and Maria Manuel Nascimento. 2016. "Fostering Critical Thinking Through Peer Review Between Cooperative Learning Groups." Revista Lusófona de Educaç ão 32: 31-45.

Sriraman, Bharath. 2004. "The Characteristics of Mathematical Creativity." The Mathematics Educator 14 (1): 19-34.

Torrance, E. Paul. 1977. "Creativity in the Classroom; What Research Says to the Teacher."

UNESCO. 2010. "Engineering: Issues, Challenges and Opportunities for Development." Online Report. Accessed June 2016. http://unesdoc.unesco.org/images/0018/001897/189753e.pdf.

Walsh, Elaine, Katie Anders, Sally Hancock, and Liz Elvidge. 2013. "Reclaiming Creativity in the Era of Impact: Exploring Ideas About Creative Research in Science and Engineering." Studies in Higher Education 38 (9): 1259-1273.

word cloud. n.d. Accessed 6 September 2017. http://www.yourdictionary.com/word-cloud.

Zhan, Wei, Rainer Fink, and Alex Fang. 2010. "Application of Statistics in Engineering Technology Programs." American Journal of Engineering Education 1 (1): 65-78.

Zhou, Chunfang. 2012. "Integrating Creativity Training into Problem and Project-Based Learning Curriculum in Engineering Education." European Journal of Engineering Education 37 (5): 488-499. 